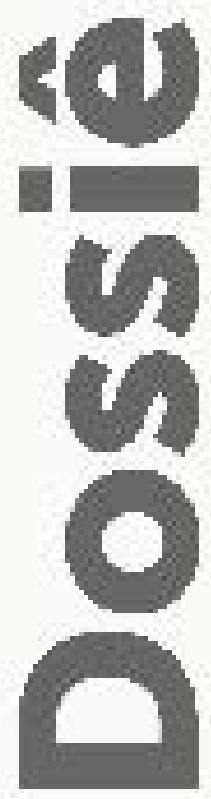

\title{
A paleopatologia e o estudo das doenças no passado
}

\author{
The paleopathology and the study of disease in \\ the past
}

\section{RESUMO}

O estudo das doenças humanas no passado, conhecida como paleopatologia, tem ajudado muito na compreensão do comportamento humano e de sua relação com o meio ambiente ao longo da história. A paleopatologia se apresenta como uma fonte substancial de informação acerca da interação homem-doenças, trabalhando com uma fonte extensa de material direto, que são os remanescentes humanos, principalmente, de sítios arqueológicos. Este artigo efetua uma revisão da literatura sobre a paleopatologia e os aspectos teóricos-metodológicos para diagnósticos de doenças no passado, abordando sua história, as especificidades do trabalho e suas limitações, apresentando elementos para uma reflexão sobre as possibilidades de colaboração com a investigação de grandes epidemias, como a do Sars-CoV-2 (COVID-19).

Palavras-chave: Paleopatologia - Arqueologia - Ossos - Esqueletos - Saúde

\begin{abstract}
The study of human diseases in the past, known as paleopathology, has contributed substantially to our understanding of human behavior and its relationship with the environment throughout history. Paleopathology presents itself as a substantial source of information about human-disease interaction, working with an extensive source of direct material - human remnants - mostly hailing from archaeological sites. This article reviews the current literature on paleopathology and the theoretical-methodological aspects of diagnosing disease in the past, addressing its history, the specificities of the work and its limitations, presenting elements for a reflection on the possibilities of collaboration with the investigation of major epidemics, such as the Sars-CoV-2 (COVID-19).
\end{abstract}

Keywords: Paleopathology - Archeology - Bones - Skeletons Health

* Doutor em Saúde Pública pela Escola Nacional de Saúde Pública da Fundação Oswaldo Cruz (ENSP/FIOCRUZ). Atualmente é Professor Adjunto III do Departamento de Antropologia do Museu Nacional/UFRJ. Atua como perito rotativo do Grupo de Trabalho Perus (GTP), que busca os desaparecidos da vala clandestina de Perus/SP. CV: http://lattes.cnpq.br/0615811843312108 


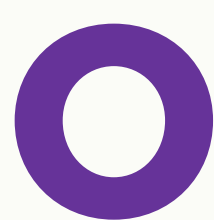

estudo das doenças humanas abrange ampla gama de fontes de informação, desde o exame direto dos doentes, bancos de dados hospitalares, até o levantamento de documentos históricos. Porém, estudar casos ocorridos no passado se torna cada vez mais difícil quanto mais recuado no tempo está situado o objeto de estudo, entre outros aspectos, devido à escassez de fontes de informação. O levantamento de textos e documentos ajudou às áreas da história e da saúde a entender surtos epidêmicos que assolaram os povos no passado, e como nossos antepassados reagiram a estas condições, adaptando-se e alterando o meio ambiente. Saber o que já se conhece sobre as doenças possibilita aplicar esquemas preventivos de futuros surtos e evitar repetir os mesmos erros do passado, como nos casos das modificações tecnológicas, do modo de produção e das relações entre as sociedades humanas, que são capazes de criar condições para mudanças radicais na manifestação de doenças há muito conhecidas. O problema reside no fato de que nem tudo foi registrado em textos, e que nem tudo que foi registrado resistiu ao tempo, de modo que era preciso buscar outros tipos de fontes para o estudo das doenças no passado como, por exemplo, a arqueologia (Lovell, 2000; Mendonça de Souza, 1992; Roberts, 2000).

Há mais de um século, a linha de pesquisa conhecida como paleopatologia vem desenvolvendo e aperfeiçoando seus instrumentos teórico-metodológicos de análise das doenças no passado, principalmente em remanescentes esqueléticos humanos e mumificados, por serem os registros diretos do fenômeno de adoecimento. Ela parte de um grande princípio, o de que os padrões de respostas e os mecanismos fisiológicos do corpo humano e de outros animais aos agentes patogênicos são os mesmos, há milhares de anos e de gerações, de forma que é possível aplicar a interpretação da clínica ao seu objeto de estudo. O esqueleto humano é dotado de plasticidade, apesar de sua estrutura dura e mineralizada, que persiste ao longo da vida, respondendo a condições de doenças com modificações em sua estrutura, que podem vir a resistir ao tempo, como registro direto da doença por milhares e, até milhões de anos (Mendonça de Souza, 1992). Os dentes são uma fonte especial de informação, pois são as partes mais duras e resistentes do esqueleto. Depois de formados, o esmalte da coroa não sofre remodelação, criando um registro fisiopatológico contínuo das lesões. Assim, a arqueologia é uma fonte de remanescentes esqueléticos humanos e de outros remanescentes humanos diretos. Consequentemente, uma fonte promissora de dados para o estudo dos processos de saúde/doença no passado, uma fonte para a paleopatologia (Cook; Buikstra, 1992; Steinbock, 1976).

Esse artigo aborda de forma geral e introdutória a paleopatologia, importante campo de saber para o estudo das condições de saúde no passado, não somente nos casos do estudo de povos ágrafos, como na contribuição para o entendimento das informações de sítios históricos. Portanto, pode ajudar a confirmar ou refutar o 
que se sabe e o que há para saber, e que não pode ser substituído por outra área de conhecimento, pois seu objeto de estudo apresenta suas especificidades, que precisam ser conhecidas e levadas em consideração (Kelley, 1989).

\section{Desenvolvimento histórico da paleopatologia}

A origem do termo "paleopatologia" é motivo de debates sobre quem teria sido o primeiro a cunhá-lo, e acerca de quem estabeleceu este campo como disciplina científica. Em geral, considera-se como pai da paleopatologia o patologista Sir Marc Armand Ruffer (1859-1917), por ter sido o primeiro a realizar estudos sistemáticos, sobretudo com múmias egípcias. Porém, não teria sido ele o primeiro a propor o uso da palavra "paleopatologia". Em um ensaio publicado em 1892 na revista norteamericana Popular Science Monthly, intitulado "Notes on Palæopathology", o Dr. Robert Wilson Shufeldt (1850-1934) propôs o uso do termo "paleopatologia" (do grego: palaiós-, antigo + -páthos-, sofrimento, doença + -lógos, estudo) para descrever todas as doenças e condições patológicas encontradas preservadas em restos de animais extintos ou fósseis". ${ }^{1}$ Posteriormente à sua proposta, o termo "paleopatologia" passou a ser registrado em dicionários, como o Funk \& Wagnalls Standard Dictionary of The English Language, de 1895. Mas foi Ruffer quem estendeu a definição para o estudo de esqueletos e múmias humanas, muito em voga no início do século $X X$, devido ao grande interesse pela arqueologia egípcia iniciada pelas invasões napoleônicas, no fim do séc. XVIII, e pela tradução da Pedra de Roseta por Champollion, em 1822. Em 1913, em um artigo publicado com o título "Studies in palæopathology in Egypt", Ruffer definiu o campo da paleopatologia como a ciência das doenças que podem ser encontradas em remanescentes humanos e animais de tempos antigos ${ }^{2}$. Em parte, essa confusão em torno da criação da palavra "Palæopathology" se deve ao fato do próprio Ruffer ter declarado em seu artigo que ele teria cunhado o termo, mas apesar de não ter tido a primazia do nome, foi ele que imprimiu a acepção ampla e moderna da palavra acerca do estudo de doenças em remanescentes humanos e de outros animais antigos, não necessariamente extintos ou fossilizados (Aufderheide; Rodríguez-Martín, 1998; Buikstra; Cook; Bolhofner, 2017; Campillo, 2001; Lovell, 2000; Rothschild; Martín, 1993; Ruffer, 1913; Waldron, 2008).

Em seus primórdios, a paleopatologia lidou com grandes lesões e fusões de ossos em peças isoladas, tratando as patologias como meras anomalias e curiosidades. Desde o séc. XVI, foram feitas descrições de casos de lesões e alterações patológicas em

1 "[...] a term here proposed under which may be described all diseased and pathological conditions found fossilized in the remains of extinct or fossil animals" (Shufeldt, 1892 apud Waldron, 2008, p. 222).

2 "[...] the science of the diseases which can be demonstrated in human and animal remains of ancient times" (Ruffer, 1913, p. 149). 
fósseis de outros animais e, mais recentemente, em humanos. As alterações em ossos isolados propiciaram o surgimento de muitas hipóteses sobre suas causas. Contudo, por se tratar de peças isoladas, não era possível relacionar com outros elementos para fundamentar e esclarecer suas etiologias. Assim, os diagnósticos não deixavam de ser meras especulações, que implicavam apenas pontualmente sobre a condição de saúde do indivíduo, e não das populações, apesar dos milhares de esqueletos e múmias examinados nas primeiras décadas do século XX (Aufderheide; Rodríguez-Martín, 1998; Lovell, 2000; Rothschild; Martín, 1993).

Uma perspectiva epidemiológica das doenças, tratadas como processos populacionais, no que concerne ao aspecto ecológico e cultural de sua expressão, só é introduzida na paleopatologia em 1930, pelo antropólogo físico Earnest Albert Hooton (1887-1954), em extenso e detalhado texto, intitulado The Indians of Pecos Pueblo: A Study of their Skeletal Remains. Nele, Hooton analisa as patologias encontradas, associando aos dados de mortalidade, alterações de suas frequências ao longo do tempo, diferenças de taxas entre grupos sociais, sexo, idade, e aspectos culturais e ecológicos, para discutir os diagnósticos. Por este estudo, Hooton é considerado por muitos como fundador da perspectiva paleoepidemiológica no estudo em paleopatologia. Sua perspectiva somente será retomada na década de 1960, com o antropólogo biológico John Lawrence Angel (1915-1986), em um estudo desenvolvido a partir deste referencial, da doença como processo populacional. Nas últimas décadas, a paleopatologia contou com significativos avanços, nos diagnósticos e interpretações bioculturais associados à aplicação de novas tecnologias de exame, como radiografias com melhores resoluções, tomografias, microscopias eletrônicas, análises químicas, técnicas imunológicas e genéticas, que resultaram em diagnósticos mais precisos, possibilitando classificação mais precisa das doenças (Aufderheide; Rodríguez-Martín, 1998; Lovell, 2000; Mays, 1998; Mendonça de Souza; de Carvalho; Lessa, 2003; Rothschild; Martín, 1993).

\section{Reação básica dos ossos}

O osso, assim como o esqueleto, é o principal material de estudo da paleopatologia. Senso comum, o osso é considerado uma estrutura inerte, sem vida, que apenas serve de suporte para tecidos e órgãos. No entanto, o osso é um órgão3 vivo, que necessita de constante renovação, num processo normal de remodelação, efetuado por meio de reabsorção óssea (osteólise) e formação óssea (osteossíntese), que reage aos mais variados estímulos bioquímicos e mecânicos, respondendo a

3 Para alguns autores, o osso é um tecido, ao mesmo tempo em que é uma estrutura complexa e dinâmica composta por diferentes tecidos, entre eles um tecido rígido mineralizado próprio deste órgão, o chamado tecido ósseo, que pode ser a causa de confusão entre o tipo de tecido (ósseo) que compõe o órgão (osso) (Gray, 1988). 
um amplo leque de organismos patogênicos, como vírus, bactérias, fungos e outros. Grosso modo, lesões e condições patológicas causam desequilíbrio entre a osteólise e a osteossíntese, levando o osso a aumentar ou diminuir o processo normal de reabsorção óssea ou de formação óssea, sendo mais comum a ocorrência de ambos os fenômenos simultaneamente. Quando há predomínio de um deles, resulta um processo erosivo (quando a reabsorção sobrepõe a formação) ou um processo proliferativo (quando a formação sobrepõe a reabsorção). Um bom exemplo deste desequilíbrio são as fraturas, que acarretam um processo de reparação do osso, com proliferação óssea na forma de um calo na porção lesionada (Gusmão; Belangero, 2009; Roberts, 2000; Steinbock, 1976).

O estresse mecânico é um dos mais importantes fatores de estímulo à remodelação óssea. A atrofia, pela paralisia do membro afetado, que não recebe estímulo mecânico pela falta de aplicação de cargas mecânicas, é um exemplo de desequilíbrio, com predomínio da atividade de reabsorção, resultando na desmineralização e perda de densidade óssea, com gradual aumento de porosidade, podendo alcançar uma condição osteoporótica. O aporte de sangue é mais um fator no equilíbrio da remodelação óssea e seu aumento (hiperemia) ou sua insuficiência (isquemia) causam interferência. $O$ incremento está associado a processos proliferativos e a redução resulta em morte celular da área afetada, em processos erosivos. As inflamações estão presentes em processos de desequilíbrio do mecanismo de remodelação óssea, em resposta aos mais diversos estímulos mecânicos e bioquímicos, deflagrando um acúmulo de fluidos, migração celular, aumento da vascularização, coleção de pus, aumento da pressão local e obstrução de vasos, isquemia e necrose, o que causa inicialmente uma irritação do osso com proliferação e reabsorção do tecido morto. Os hormônios constituem importante fator para a manutenção do osso, controlando seu crescimento, remodelação, mobilização de cálcio. Seu desequilíbrio acarreta uma alteração nos processos de reabsorção e produção de osso, como no caso do hiperparatiroidismo, quando há aumento da secreção de hormônio da paratireóide, que estimula a atividade das células osteoclásticas (responsáveis pela remoção de osso), resultando em perda generalizada de massa óssea, pelo aumento do processo erosivo. As neoplasias ou tumores (proliferação desordenada de células) também são produtores de desequilíbrio, no processo de remodelação óssea, causando tanto uma formação quanto reabsorção óssea. Geralmente, lesões erosivas são associadas a tumores invasivos, enquanto os proliferativos são mais vinculados aos tumores de crescimento lento (Mays, 1998; Steinbock, 1976).

\section{Paleopatologia e suas especificidades}

A seguinte pergunta é frequente, em escavações arqueológicas, em meio aos 
achados de remanescentes esqueléticos humanos: qual foi a causa da morte dessas pessoas? A paleopatologia é convocada a responder, pois aparentemente é esta a sua especialidade: o entendimento dos traumas e das doenças que conduziram aquelas pessoas à morte. Contudo, a paleopatologia concerne mais sobre a forma como as pessoas viveram do que como morreram. De fato, mesmo com meticulosa escavação, com boa preservação dos ossos e cuidadoso exame dos esqueletos dificilmente será possivel determinar como morreram. Evidências de lesões traumáticas mortais são relativamente raras em esqueletos arqueológicos e, em geral, as mortes são por causas naturais por doenças. Tais condições, para infelicidade do paleopatologista, não deixam registros corporais, apesar de muitas doenças e traumas causarem marcas nos ossos, mas outras causas, como infarto do miocárdio e infecções agudas gastrointestinais e respiratórias não deixam quaisquer marcas. Esta afirmação é ainda mais verdadeira quando se trata de doenças com quadro clínico de evolução aguda, que em pouco tempo há piora das condições de saúde e o indivíduo morre ou, ao contrário, há melhora e recuperação sem sinais. $O$ tecido ósseo possui uma resposta relativamente lenta à lesão ou à doença: são necessárias pelo menos duas semanas para que os sinais das respostas se tornem visiveis a olho nu ou ao menos sete dias, para formação de sinais microscópicos de resposta óssea. Em geral, são necessários quadros de adoecimento de evolução crônica e demorada para que o tecido ósseo apresente algum sinal de resposta visível, seja por falecimento ou cura. Assim, entre as doenças agudas e crônicas, a paleopatologia tem seu leque de sinais de doenças restrito apenas às doenças crônicas (Byers, 2002; Lovell, 2000; Mays, 1998; Ortner, 1992).

Este é um dos limites do estudo em paleopatologia, uma vez que os sinais de doenças agudas são raros e quase todos os sinais encontrados consistem em evidências de doenças crônicas. Nesse sentido, dentre as grandes epidemias que se tem registro na história humana, é provável que poucas evidências diretas se encontrem nos esqueletos, pois esses episódios epidêmicos são rápidos, com quadros agudos que conduzem à morte em curto prazo ou ocorre a cura. Dentre as doenças infecciosas, aquelas causadas por vírus raramente deixam sinais ósseos e, em muitos casos, as enfermidades virais foram responsáveis por grandes eventos históricos de epidemias, como a varíola e o sarampo, que devastaram populações nativas americanas no século $\mathrm{XVI}$, sem deixar evidências nos esqueletos arqueológicos. São as doenças infecciosas de origem bacteriana que podem afetar o esqueleto, por acarretar respostas inflamatórias e produção de pus. Mas, nem todas as enfermidades crônicas provocam resposta do tecido ósseo e aquelas que provocam têm a característica de demandar muito tempo para que seus sinais se tornem visíveis, pois são necessários anos e décadas para tanto (Ortner, 1992).

Como exemplo, as treponematoses, que somente no terceiro estágio de evolução da doença, passados entre um e vinte anos, surgem lesões ósseas. A maioria 
das doenças crônicas, que muitas vezes levaram anos de desenvolvimento da patologia, para deixar sinais no osso, provavelmente não está associada à morte, já que a própria cronicidade pode estar relacionada à resistência à doença. Nesse sentido, é possível afirmar que a paleopatologia trata mais da morbidade do que da mortalidade. Dessa forma, aborda o estilo de vida da população, suas características culturais e sua relação com o meio ambiente (Mays, 1998; Ortner, 1992).

Quando lesões de doenças infecciosas são encontradas, trata-se de prova de que a enfermidade foi crônica o suficiente para que o osso respondesse a ela. Em estudo de casos antigos, quando os tratamentos não eram eficientes ao ponto de interferir na história natural da doença, ${ }^{4}$ a presença de lesões indica que se tratava de indivíduos resistentes o bastante para sobreviver um tempo suficiente para que a doença deixasse marcas em seus ossos, mas não fortes a ponto de não adoecerem, ou fracos para morrerem rapidamente antes de a doença deixar suas marcas. Dessa forma, somente indivíduos com média resistência apresentam sinais de doenças em seus ossos, nas séries esqueléticas arqueológicas. Em surtos epidêmicos como os que atingiram as populações nativas americanas no século XVI, há um fator complicador que pode explicar a ausência de sinais das infecções: a falta de experiência anterior com o patógeno. Neste caso, a doença não encontra resistência dos indivíduos, evoluindo de forma aguda e matando rapidamente, sem deixar sinais. Assim, séries esqueléticas inteiras de populações não resistentes provavelmente não terão qualquer indício de resposta do tecido ósseo à epidemia que os atingiu, apresentando esqueletos com aspecto normal, como os de indivíduos saudáveis que nunca adoeceram, apesar de terem adoecido e morrido da enfermidade que causou a epidemia (Lovell, 2000; Ortner, 1992).

Este é o assim chamado paradoxo osteológico, proposto por Wood et al. (1992), que considera que o perfil de morbidade da série esquelética arqueológica pode não corresponder ao da população viva que representa. Portanto, uma alta frequência de esqueletos com sinais patológicos pode não significar população epidemicamente doente, assim como uma baixa frequência de esqueletos com sinais patológicos pode não indicar uma população saudável. Em outras palavras, uma série esquelética sem sinais de doença tanto pode se tratar de uma população pouco resistente, que morreu logo sem desenvolver as lesões ósseas, apesar de a doença ter se espalhado por grande parte da população, ou pode se tratar de uma população muito resistente que nem adoeceu, ou se curou rapidamente sem espalhar a doença, e também não desenvolveu lesões ósseas. Por outro lado, uma série esquelética com muitos sinais ósseos da doença provavelmente representa aquela população medianamente resistente que adoeceu,

4 "todas as interrelações do agente, do hospedeiro e do meio ambiente que afetam o processo global e seu desenvolvimento, desde as primeiras forças que criam o estímulo patológico no meio ambiente ou em qualquer outro lugar, passando pela resposta do homem ao estímulo, até as alterações que levam a um defeito, invalidez, recuperação ou morte" (Leavell; Clark, 1976 apud Nunes, 1978, p. 506). 
conseguiu resistir o suficiente para evoluir o quadro e desenvolver lesões ósseas, mas que necessariamente a doença não se espalha de forma epidêmica, para apresentar uma frequência relativamente alta de esqueletos com sinais da doença (Lovell, 2000; Ortner, 1992; Wood et al., 1992).

Essas especificidades da resposta dos ossos às condições patológicas propiciam, consequentemente, uma subestimativa das doenças na população e um erro de interpretação de suas frequências. A causa desta subestimativa não reside somente na capacidade de resistência do indivíduo à doença, como também depende das próprias características da enfermidade e de sua história natural. Apesar de se tratar de uma doença crônica de longo prazo capaz de afetar o osso, causando sinais de resposta à sua presença, nem sempre a doença acarreta sinais ósseos. Um bom exemplo é a tuberculose, uma doença capaz de afetar o esqueleto, em uma pequena parcela dos indivíduos, em média em torno de cinco a sete por cento dos casos (Steinbock, 1976, p. 175). Na eventualidade de que uma boa parcela da população adoeça de tuberculose, apenas uma parte dos casos apresentará sinais ósseos. A presença da doença e a cronicidade do quadro não constitui certeza de gerar sequelas ósseas, pois a evolução do quadro não necessariamente acarreta afetação do osso e formação de sinais. Porém, esta média de casos de tuberculose com sinais ósseos ou de outras doenças similares pode variar para mais ou para menos, a depender da população, com taxa menor naquelas com baixa resistência, pois as pessoas em geral morrem cedo sem sequelas ósseas, mesmo a doença afetando uma maior parcela da população (alta prevalência ${ }^{5}$ ), e tendo taxa maior naquelas que tem média resistência, pois se curam ou morrem mais tarde com lesões no esqueleto, mesmo a doença afetando uma menor parcela da população (baixa prevalência). Novamente, essa diferença de taxas entre uma população menos resistente com alta prevalência da doença, e uma mais resistente com baixa prevalência da doença pode conduzir a uma interpretação equivocada de que a série esquelética com maior frequência de esqueletos afetados seria a que a população em vida tinha maior prevalência e vice-versa, o que é uma total inversão dos fatos (Lovell, 2000; Mays, 1998; Steinbock, 1976).

De certo modo, estudar ossos secos tem suas vantagens, se comparado aos estudos clínicos e necropsiais. Muitas das lesões ósseas são invisíveis aos exames de imagem clínicos (radiografias, tomografias, ressonâncias magnéticas), como os pequenos e discretos sinais de periostoses na face interna das costelas associados à tuberculose pulmonar, que também não são percebidos nas autópsias, por estarem recobertos por tecidos moles que os escondem, mas que podem ser facilmente observados em um exame cuidadoso do esqueleto seco. Tanto as chamadas lesões líticas (ou erosivas), que também são encontradas em vértebras e costelas como sinais

5 Prevalência é definida como a frequência de casos na população que tem a doença em determinado momento (Pizzichini et al., 2020). 
de tuberculose pulmonar quanto as lesões formativas (ou proliferativas) são apenas visíveis em exames radiográficos a partir de trinta a cinquenta por cento da alteração da densidade óssea, seja pela remoção, seja pela deposição de material ósseo. Tal condição produz um problema a ser considerado no estudo em paleopatologia: os resultados dos estudos clínicos não podem ser diretamente comparados de forma não criteriosa aos dos estudos paleopatológicos, uma vez que as frequências e o envolvimento dos ossos não necessariamente correspondem, em ambos os estudos, por diferenças de percepções. Por outro lado, estudar ossos secos traz desvantagens, frente aos estudos clínicos e necropsiais, uma vez que estes contam com uma vasta gama de possibilidades de exames clínicos e laboratoriais que, além da possibilidade de efetuar uma anamnese, conta com a presença de todos os tecidos e órgãos que compõem o corpo, enquanto para a paleopatologia restam apenas ossos secos, muitas vezes de esqueletos incompletos, quando muito com tecidos mumificados, de indivíduos há muito mortos (Kelley, 1989; Mays, 1998; Rothschild; Martín, 1993).

Apesar dessa relativa facilidade de a paleopatologia identificar as lesões patológicas, o estudo paleopatológico conta com mais um fator limitante, quanto aos sinais de doenças: o limite de resposta ósseo. O osso tem um espectro de respostas relativamente restrito, podendo responder a uma doença com a produção de osso, em processo proliferativo, ou retirando osso, em processo erosivo. Essa limitação acarreta semelhança entre os sinais de diferentes doenças e lesões ou, até, a similaridade de sinais por diferentes doenças. Em geral, a maioria dos sinais ósseos de enfermidades é inespecífica, de maneira que não é possível a atribuição de um diagnóstico específico. Um bom exemplo são as lesões destrutivas da abertura piriforme (cavidade nasal), que pode ser causada por distintas condições patológicas, inclusive treponematoses, lepra, tuberculose óssea, leishmaniose, tumores e traumas (Ortner, 1992).

As periostoses, sinais de reação do periósteo que recobre os ossos, são frequentes e presentes em uma diversidade de lesões e condições patológicas. Por ter um limitado espectro de respostas, em geral as periostoses são semelhantes, de forma que não permitem a elaboração de um diagnóstico específico acerca da causa da resposta do periósteo. As hiperostoses poróticas constituem outro sinal inespecífico. Geralmente estão localizadas nas lâminas externas dos ossos parietais, podendo envolver o osso frontal, e resultam da expansão da medula óssea em resposta ao aumento da produção de células sanguíneas. Associadas frequentemente a deficiências ferroprivas, anemias por deficiência de ferro, as condições de anemias podem ser provocadas por diversos fatores, não somente a deficiência de ferro, apesar desta causa ser mais comum que as demais. Um exemplo de enfermidade que causa anemia é o escorbuto, uma condição de deficiência grave de vitamina $C$, que provoca hematomas e sangramentos, levando a uma demanda de aumento da produção de células sanguíneas, provocando o crescimento das medulas parietais e o aparecimento dos sinais de hiperostose porótica 
(Mays, 1998; Ortner, 1992; Steinbock, 1976).

Os chamados sinais patognomônicos (do grego: páthos-, sofrimento, doença + -gnomon, indicador), específicos de uma doença, são muito raros e restritos a poucas enfermidades, como no caso das treponematoses, que contam com sinais peculiares no crânio, derivados das lesões gomatosas ${ }^{6}$, e periostoses com características próprias nos ossos das pernas. Contudo, mesmo para esta doença não é possível distinguir a qual enfermidade correspondem estes sinais patognomônicos, uma vez que as treponematoses compõem um conjunto de patologias causadas pela bactéria do gênero Treponema, que inclui a sífilis venérea, a sífilis endêmica (também conhecida como bejel), a bouba e a pinta. Com exceção da última, a pinta, as outras apresentam sinais ósseos similares, de modo que é difícil distinguir entre as três doenças (Mays, 1998; Steinbock, 1976).

\section{Diagnóstico em paleopatologia}

O método básico em paleopatologia é o observacional, e a descrição é o processo que possibilita uma resposta, sem ir além do que os dados indicam. Mas, antes de começar a descrever uma lesão, é necessário saber se a alteração do osso encontrada é um sinal de doença. Primeiro, é preciso determinar se o que está alterado no osso ocorreu em vida ou se é resultado de danos após a morte, quando o esqueleto se encontrava no solo. Para esse tipo de alteração, vulgarmente é dado o nome de tafonomia7 (do grego tháfos-, sepultamento + -nómos, leis), que são todas e quaisquer alterações que ocorram no corpo desde a sua deposição no solo, inumação, até a sua retirada, exumação. Os sinais encontrados nos ossos que não resultaram de condições patológicas, mas de alterações por fatores naturais do solo (composição química, pH etc.), fatores climáticos (umidade, variação de temperatura, insolação etc.), fatores bióticos (animais carniceiros, insetos, microorganismos, passagens de raízes e plantas, etc), são "alterações tafonômica", sendo a tafonomia a ciência dedicada a elas. Diferente dos processos patológicos, que levam o esqueleto a responder removendo osso e/ou formando osso, os processos tafonômicos não têm condições de formar osso, mas apenas retirar esse tecido. O problema então reside em distinguir alterações erosivas/ destrutivas encontradas no osso, que podem ter sido tanto causadas por doenças quanto por processos pós-deposicionais (Mays, 1998; Ortner, 1992).

Os processos patológicos erosivos do osso também envolvem algum processo

6 São lesões derivadas da formação no estágio terciário (entre 1 e 20 anos) de massas granulomatosas, nodulares, no tecido ósseo ou tecidos moles adjacentes, levando à formação de uma cavitação no osso por erosão, muitas vezes associada a uma infecção piogênica secundária e sequestro (fragmento de osso necrosado separado do osso vivo), e que com sua cicatrização formam marcas características denominadas por Virchow, em 1896, de caries sicca (Lopes; Powell; Santos, 2010; Steinbock, 1976).

7 Tafonomia é a ciência que estuda os processos de preservação dos restos orgânicos no registro sedimentar e como esses processos afetam a qualidade do registro fóssil (Behrensmeyer; Kidwell; Gastaldo, 2000). 
de remodelação, com formação de osso. A observação cuidadosa da alteração erosiva/ destrutiva do osso poderá distinguir se as bordas de osso destruído apresentam aspecto áspero, o que evidenciaria uma ausência de remodelação óssea, ou se as bordas são arredondadas, o que provaria que aquela erosão ocorreu em vida, devido à presença de sinais de remodelação. Outro sinal que pode ajudar a distinguir é a remodelação do osso trabecular. ${ }^{8}$ Nas lesões patológicas erosivas, o osso esponjoso muitas vezes fica exposto, como também fica nas erosões tafonômicas, mas por vezes há algum grau de remodelação da arquitetura deste osso esponjoso, em resposta à doença, inclusive quando o processo de remoção do osso é predominante, o que pode ajudar a distinguir da arquitetura normal do osso esponjoso, e apontar um sinal de doença (Mays, 1998; Ortner, 1992).

Antes de descrever os sinais patológicos, é preciso determinar se a alteração encontrada não seria uma variação normal da anatomia do esqueleto, conhecida como caractere epigenético, caractere discreto ou, ainda, caractere não-métrico. Os caracteres epigenéticos geralmente são pequenas alterações da forma normal do osso e do dente, frequentemente não associados a qualquer condição patológica. Não há certeza acerca do que conduziu à formação da maioria das v variações, mas considerase a existência de algum grau de controle genético em todas elas, em maior ou menor proporção de cada variação, que atua de forma conjunta com fatores externos aos genes para sua ocorrência (Mays, 1998). O esqueleto humano possui mais de quatrocentos caracteres deste tipo, muitos são raros, com frequências muito baixas nas populações ou, até inexistentes em algumas populações, e pouco conhecidos (Saunders, 1989)

Essas variações morfológicas normais envolvem: a variação numérica de ossos e dentes (por exemplo, ausência dos 3ำ molares, os dentes do siso; a presença de dentes a mais, os dentes supranumerários; a presença de ossículos nas suturas ${ }^{9}$, principalmente da sutura lambidóidea, ${ }^{10}$ os chamados ossos suturais; e a presença de pequenos ossículos que se formam nos pés e mãos, geralmente ossos sesamoides); a anomalia de fusão do osso (por exemplo, o metopismo, que é a persistência por não fusão da sutura metópica, ${ }^{11}$ que no recém-nascido separa as duas metades do osso frontal do crânio, e que nos primeiros anos de vida se fundem); a variação no número de forames ${ }^{12}$ nos ossos (por exemplo, a variação do número de forames dos ossos parietais do crânio na região obélica, ${ }^{13}$ podendo variar para mais ou para menos); a

8 O osso é macroscopicamente formado por dois tipos de tecido ósseo: cortical/compacto e trabecular/ esponjoso. O osso compacto recobre todo o osso, sendo mais espesso no corpo (diáfise) dos ossos longos. 0 osso esponjoso tem a forma semelhante a uma estrutura de colmeia e é encontrado no interior das extremidades (epífises) dos ossos longos, no interior dos ossos curtos, planos e irregulares (Mays, 1998; White; Black; Folkens, 2012).

9 Suturas são articulações fibrosas que unem vários ossos do crânio (White; Black; Folkens, 2012).

${ }^{10}$ Articulação que une o osso occipital aos ossos parietais (White; Black; Folkens, 2012).

11 Ou sutura frontal, a articulação que une as duas metades laterais do osso frontal, e que se funde ainda na infância (White; Black; Folkens, 2012).

12 Aberturas nos ossos, geralmente para passagem de vasos sanguíneos e nervos (White; Black; Folkens, 2012).

13 Porção da sutura sagital (articulação entre os dois parietais) que se localiza entre os forames parietais (quando presentes) (White; Black; Folkens, 2012). 
variação de facetas articulares (por exemplo, as chamadas "facetas de agachamento", que se formam no osso tálus e na tíbia e em superfícies não articulares, estão associadas ao hábito de permanecer agachado); as hiperostoses, variação caracterizada pela deposição de osso em excesso (por exemplo, a presença dos tóros mandibulares, maxilares e palatinos; e, a formação das exostoses de meato acústico externo ${ }^{14}$ ); as hipo-ostoses, variação causada pela deficiência de deposição de osso (por exemplo, a presença do forame supracondilar do úmero, localizado na extremidade distal do osso, e que em vida é preenchido por uma membrana não calcificada); e, a variação na forma dos dentes (por exemplo, os chamados "dentes em pá", alterações da forma dos dentes incisivos, que pode tanto afetar a face lingual quanto a face vestibular) (Mann; Hunt; Lozanoff, 2016; Mays, 1998).

Quanto maior a familiaridade do pesquisador com a anatomia normal do esqueleto, maiores são suas chances de identificar as variações normais, sem confundilas com alterações patológicas. Ainda que o pesquisador não conheça exatamente qual é a característica epigenética, devido à sua experiência com a anatomia, ele poderá reconhecer o aspecto como pouco frequente, normal da anatomia (Mann; Hunt; Lozanoff, 2016).

Assim, as alterações ósseas encontradas no esqueleto não são decorrentes de processos tafonômicos nem variações normais da anatomia do esqueleto. Ao se assegurar de que se trata de sinais de doenças ou lesões, o próximo passo é efetuar o diagnóstico. Todo diagnóstico em paleopatologia deve partir da descrição e documentação detalhada das alterações, o que pode aumentar as chances de diagnósticos mais específicos, segundo quatro critérios: 1ำ a aparência da lesão; 2ำ a localização da lesão no osso; 3 a distribuição das lesões no esqueleto; e 4a distribuição das lesões na população. Estas descrições devem contemplar tanto o exame a olho nu quanto lançar mão do uso de lupas de médio e grande aumento ou, até, de microscópios, para estabelecer a presença de respostas ósseas incipientes (Lovell, 2000; Ortner, 1992).

A partir da ordem dos quatro critérios, 1ำ a aparência da lesão: deve se estender para além de uma descrição superficial, como um "buraco", um "sulco", uma "perfuração", uma "protuberância", um "depósito", uma "camada", uma "crista", uma "ponta". A descrição da lesão deve detalhar seus vários aspectos, como a forma (por exemplo, um buraco pode ter o formato estrelado, redondo, alongado, com margens levantadas, abaixadas, com bordas definidas, arredondadas, afiadas, fundo plano, em "V", em "U" etc.), as dimensões (se está presente em toda a diáfise, se está restrito a uma pequena porção do osso etc.), a textura (de aspecto liso, poroso, rugoso, firme, friável, etc.) (Campillo, 2001).

2 a localização no osso deve, sempre que possivel e necessário, levar em

14 Crescimento ósseo na orelha externa (White; Black; Folkens, 2012). 
consideração os acidentes anatômicos (tuberosidades, rugosidades, linha, sulcos, cristas, côndilos, cabeças, etc.) para referir sua localização na porção do osso (epífise, terços da diáfise, articulações, etc.) e como se apresenta por todo o osso (discreto, multifocal, difuso, etc.). Uma recomendação importante no momento da descrição da localização é o uso da Terminologia Anatômica Internacional vigente, para normatizar a descrição e facilitar a troca e comparação dos dados descritos (Sociedade Brasileira de Anatomia, 2001; Campillo, 2001; Gonçalves; Cabral; Grecco, 2020).

3ำ a descrição no esqueleto deve contemplar a distribuição das lesões (se são unilaterais ou bilaterais; simétricas ou assimétricas; concentradas em alguma região do corpo, como a cabeça, o tronco, os membros; se na porção inferior ou superior; etc.) (Campillo, 2001; Lovell, 2000).

4ํ e último, a distribuição das lesões na população deve considerar a identificação dos casos por sexo (se somente femininos, somente masculinos ou em ambos os sexos) e idade (se subadulto ou adulto; criança, jovem, adulto ou idoso; etc.). As descrições devem ser acompanhadas por fotografias e diagramas, que auxiliam uma reflexão sobre as características das lesões, enriquecendo as descrições com detalhes (Campillo, 2001; Lovell, 2000; Ortner, 1992; Rothschild; Martín, 1993).

Uma vez que todas as lesões foram descritas detalhadamente e localizadas nos ossos, no esqueleto e na população, seus padrões podem ser comparados com modelos de referências: clínicos; forenses e históricos. Neste processo de comparação, a forma, a localização e a distribuição das lesões servem, em conjunto, para comparar estes modelos de referências, para identificar os quadros patológicos mais prováveis. Porém, há um problema, na comparação de padrões de sinais de doenças em esqueletos arqueológicos com modelos clínicos e forenses: a interferência sobre a história natural das doenças, pela presença da medicina moderna, com uso de drogas e terapias efetivas, principalmente, pela introdução de antibióticos. A partir desse dado, há debates em torno da busca da paleopatologia por modelos históricos de casos documentados, anteriores à introdução dos antibióticos efetivos. Ortner e Putschar (1981) propõem, por exemplo, o uso de coleções médicas e museológicas datadas entre os anos de 1750 e 1930, uma vez que neste período ainda não existiam medicações e terapias efetivas o suficiente para interferir na história natural das doenças, e os diagnósticos médicos eram razoavelmente seguros. Porém, deve-se considerar que muitas doenças foram diagnosticadas e classificadas nas últimas décadas, e que não poderão ser diagnosticadas de forma específica a partir dessas coleções históricas (Lovell, 2000; Mays, 1998).

\section{Considerações finais}

Apesar do significativo avanço da paleopatologia nas últimas décadas, 
sobretudo com a aplicação de tecnologias modernas para análise dos remanescentes esqueléticos (Raio X digital, Tomografia Computadorizada de Alta Resolução - TCAR, Microscopia Eletrônica de Varredura - MEV, DNA antigo - aDNA, etc), ainda existem problemas a serem corrigidos e aprimorados, principalmente no que diz respeito aos seus métodos e teorias. Um dos problemas mais frequentes reside nos diagnósticos dos casos patológicos. Tal quadro é decorrente de uma variedade de situações, dentre as quais, a de entender as possibilidades de diagnósticos para condições patológicas de doenças específicas, e a atribuição de diagnóstico específico para condições patológicas inespecíficas (Ortner, 1992).

O diagnóstico é o último passo do processo de análise, mas nem sempre será possível dar este passo. Mais importante do que elaborar o diagnóstico é efetuar uma detalhada descrição das lesões ósseas, com uso de uma metodologia rigorosa, com termos padrões para viabilizar um entendimento de todos os pesquisadores. Dessa forma, a paleopatologia trata do estilo de vida das populações, suas características culturais e sua relação com o meio ambiente, em detrimento de seu sofrimento com as doenças ou de sua morte. No caso de grandes eventos epidemiológicos, não necessariamente a paleopatologia poderá colaborar, pelas especificidades da área.

A ocorrência de uma grande epidemia ou, até, de uma pandemia como a do Sars-CoV-2 (COVID-19), não necessariamente será registrada em esqueletos, com possibilidade, no futuro, de análise e diagnóstico, seja pelo tempo para desenvolvimento de sinais ósseos, na história natural da doença, pela morte em pouco tempo ou pela recuperação, seja porque a doença não acarreta qualquer resposta do esqueleto. Contudo, a mudança de comportamento da população em meio a essas epidemias, e especificamente à pandemia do Sars-CoV-2 (COVID-19), poderá se refletir na alteração significativa do padrão de sinais de lesões ósseas, no quadro patocenótico. ${ }^{15}$ Essas mudanças ocorrem por diferentes razões, dentre elas, por interferência na história natural de outras doenças, pelo balanço dos sinergismos e antagonismos nas doenças de significado coletivo e/ou nas modificações das condições de vida, pelas transformações socioambientais e das relações parasito-hospedeiro, propiciando um aumento ou redução de cada um dos sinais de outras doenças, em comparação com períodos de estabilidade endêmica (Mendonça de Souza, 1996).

A paleopatologia é uma ciência que busca entender o contexto cultural e o comportamento humano, por intermédio do estudo de sinais de doenças. As enfermidades e a morte não são o fim da paleopatologia, mas somente seus meios de alcançar seus fins.

\footnotetext{
15 [...] conjunto de doenças, ou condições patológicas a elas associadas, que caracterizam um grupo ou população humana do passado" (Mendonça de Souza, 1995, p. 43).
} 


\section{Referências bibliográficas}

AUFDERHEIDE, Arthur C.; RODRÍGUEZ-MARTíN, Conrado. The Cambridge Encyclopedia of Human Paleopathology. Cambridge, UK: Cambridge University Press, 1998. 498 p.

BEHRENSMEYER, Anna K.; KIDWELL, Susan M.; GASTALDO, Robert A. Taphonomy and paleobiology. Paleobiology, Cambridge, v. 26, n. 4, p. 103-147, 2000. Suplement. https://doi.org/10.1017/S0094837300026907

BUIKSTRA, Jane; COOK, Della. Paleopatologia. In: ARAÚJO, Adauto José Gonçalves de; FERREIRA, Luiz Fernando (Ed.). Paleopatologia e Paleoepidemiologia: estudos multidisciplinares. Rio de Janeiro: Escola Nacional de Saúde Pública, 1992. p. 41-85. https:// doi.org/10.1016/j.ijpp.2017.08.005. PMid:29198402.

BUIKSTRA, Jane; COOK, Della; BOLHOFNER, Katelyn. Introduction: Scientific rigor in paleopathology. International Journal of Paleopathology, New York, v. 19, p. 80-87, dec. 2017.

BYERS, Steven N. Introduction to Forensic Anthropology: A Textbook. Boston: Allyn and Bacon, 2002. $502 \mathrm{p}$.

CAMPILLO, Domènec. Introducción à la Paleopatología. Barcelona: Bellaterra, 2001. $591 \mathrm{p}$.

GONÇALVES, Giuliano Roberto; CABRAL, Richard Halti; GRECCO, Leandro Henrique. A Importância do Emprego da Terminologia Anatômica nas Ciências da Saúde. Revista Brasileira de Educação Médica, Brasília, v. 44, n. 4, e112, 2020. https://doi.org/10.1590/ 1981-5271v44.4-20200180

GRAY, Henry. Gray Anatomia. 29. ed. Rio de Janeiro: Guanabara Koogan S.A., 1988. 1147 p.

GUSMÃO, Carlos Vinícius Buarque de; BELANGERO, William Dias. Como a célula óssea reconhece o estímulo mecânico? Revista Brasileira de Ortopedia, São Paulo, v. 44, n. 4, p. 299-305, 2009. https://doi.org/10.1590/50102-36162009000400003. PMid:27022510.

KELLEY, Mark A. Infectious Disease. In: ISCAN, Mehmet Yasar; KENNEDY, Kenneth A. R. (Ed.). Reconstruction of life from the skeleton. New York: Alan R. Liss, Inc., 1989. p. 191-199.

LOPES, Célia; POWELL, Mary Lucas; SANTOS, Ana Luísa. Syphilis and cirrhosis: A lethal combination in a XIX century individual identified from the Medical Schools Collection at the University of Coimbra (Portugal). Memorias do Instituto Oswaldo Cruz, Rio de Janeiro, v. 105, n. 8, p. 1050-1053, 2010. https://doi.org/10.1590/S007402762010000800016. PMid:21225204. 
LOVELL, Nancy C. Paleopathological Description and Diagnosis. In: KATZENBERG, Mary Anne; SAUNDERS, Shelley R. (Ed.). Biological Anthropology of the Human Skeleton. First ed. Hoboken, NJ: John Wiley \& Sons, Inc., 2000. p. 211-242.

MANN, Robert W.; HUNT, David R.; LOZANOFF, Scott. Photographic regional atlas of non-metric traits and anatomical variants in the human skeleton. Springfield, Illinois: Charles C Thomas, 2016. 744 p.

MAYS, Simon. The archaeology of human bones. First ed. New York: Routledge, 1998. $242 \mathrm{p}$.

MENDONÇA DE SOUZA, Sheila Maria Ferraz. Traumatismos vertebrais como indicadores de atividade física na população da Furna do Estrago, Pernambuco, Brasil. In: ARAÚJO, Adauto José Gonçalves de; FERREIRA, Luiz Fernando (Ed.). Paleopatologia e Paleoepidemiologia: estudos multidisciplinares. Rio de Janeiro: Escola Nacional de Saúde Pública, 1992. p. 123-139.

MENDONÇA DE SOUZA, Sheila Maria Ferraz. Estresse, doença e adaptabilidade: estudo comparativo de dois grupos pré-históricos em perspectiva biocultural. 1995. Tese (Doutorado em Saúde Pública) - Escola Nacional de Saúde Pública, Fundação Oswaldo Cruz, Rio de Janeiro, 1995. 254 p.

MENDONÇA DE SOUZA, Sheila Maria Ferraz. Anemia e adaptabilidade em um grupo costeiro pré-histórico: uma hipótese patocenótica. In: CONGRESSO DE LA ASSOCIACION LATINOAMERICANA DE ANTROPOLOGIA, 4., 1996, Buenos Aires. Anais [...]. Buenos Aires: [s. n.], 1996. Tema: Salud y Enfermedad de las poblaciones Aborigenes y Cosmopolitas de America.

MENDONÇA DE SOUZA, Sheila Maria Ferraz; DE CARVALHO, Diana Maul; LESSA, Andrea. Paleoepidemiology: Is There a Case to Answer? Memorias do Instituto Oswaldo Cruz, Rio de Janeiro, v. 98, p. 21-27, jan. 2003. Suplemento 1. https://doi.org/10.1590/ S0074-02762003000900005. PMid:12687758.

NUNES, Everardo Duarte. Análise de alguns modelos utilizados no ensino das ciências sociais nas escolas médicas: bases teóricas. Revista de Saúde Pública, São Paulo, v. 12, n. 4, p. 506-515, dez. 1978. https://doi.org/10.1590/S0034-89101978000400010. PMid:752922.

ORTNER, Donald J. Skeletal Paleopathology: probabilities, possibilities and impossibilities. In: VERANO, John W.; UBELAKER, Douglas H. (Ed.). Disease and demography in the Americas. Washington (D.C.): Smithsonian Institution Press, 1992. p. 5-13.

ORTNER, Donald J.; PUTSCHAR, W. G. J. Identification of pathological conditions in human skeletal remains. 1 ed. Washington (D.C.): Smithsonian Institution Press, 1981. 664 p. https://doi.org/10.5479/si.00810223.28.1

PIZZICHINI, Márcia Margaret Menezes et al. Medidas de frequência: calculando prevalência e incidência na era do COVID-19. Jornal Brasileiro de Pneumologia, São Paulo, v. 46, n. 3, e20200243, 2020. https://doi.org/10.36416/1806-3756/e20200243. PMid:32556028 PMCid:PMC7572287. 
ROBERTS, Charlotte. Infectious Disease in Biocultural Perspective: past, present and future work in Britain. In: COX, Margaret; MAYS, Simon. (Ed.). Human Osteology: In Archaeology and Forensic Science. London: Greenwich Medical Media, 2000. P. 145-162.

ROTHSCHILD, Bruce M.; MARTIN, Larry D. Paleopathology: disease in the fossil record. Boca Raton, Fla: CRC Press, 1993. 386 p.

RUFFER, Marc Armand. Studies in palæopathology in Egypt. The Journal of Pathology and Bacteriology, London, v. 18, n. 1, p. 149-162, 1913. https://doi.org/10.1002/ path.1700180116.

SAUNDERS, Shelley R. Nonmetric Skeletal Variation. In: ISCAN, Mehmet Yasar; KENNEDY, Kenneth A. R. (Ed.). Reconstruction of life from the skeleton. New York: Alan R. Liss, Inc., 1989. p. 95-108.

SHUFELDT, Robert Wilson. Notes on Palæopathology. Popular Science Monthly, New York, v. 41, p. 679-684, 1892.

SOCIEDADE BRASILEIRA DE ANATOMIA. Terminologia Anatomica Internacional. São Paulo: Manole, 2001. $259 \mathrm{p}$.

STEINBOCK, Ted. Paleopathological Diagnosis and Interpretation: Bone Diseases in Ancient Human Populations. Springfield: Charles C Thomas, 1976. 423 p.

WALDRON, Tony. Palaeopathology. Cambridge, UK: Cambridge University Press, 2008. 279 p. https://doi.org/10.1017/CBO9780511812569.

WHITE, Tim D.; BLACK, Michael T.; FOLKENS, Pieter A. Human Osteology. Third ed. Burlington, MA: Elsevier, 2012. 688 p.

WOOD, James W. et al. The osteological paradox. Problems of inferring health from the skeleton. Current Anthropology, Chicago, v. 33, p. 343-370, aug./oct. 1992. https://doi. org/10.1086/204084.

Recebido em: 30 de setembro de 2020

Aprovado em: 19 de dezembro de 2020 